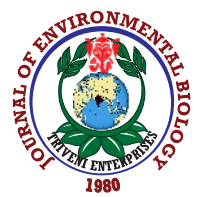

\title{
Molecular characterization of native pink pigmented facultative methylotrophs of chilli and their induced systemic resistance mechanism in management of anthracnose
}

\author{
S. Santosh ${ }^{1,2 *}$ and M.N. Sreenivasa ${ }^{2}$ \\ 'Division of Crop Production, ICAR-Central Institute for Cotton Research, Nagpur-440 010, India \\ ${ }^{2}$ Department of Agricultural Microbiology, University of Agricultural Sciences, Dharwad- 580005 , India \\ *Corresponding Author Email : abdhi2050@gmail.com
}

\begin{abstract}
Methodology: The selected native PPFMs were identified by analysis of 16S rRNA gene sequence. These isolates along with reference strain (Methylobacterium extorquens AM1) were inoculated to healthy chilli plants. The pathogen (Colletotrichum capsici) was later inoculated to these chilli plants, and induced systemic resistance (ISR) molecules were estimated at different intervals from one day after challenge inoculation of pathogen (DAI) upto 7 DAI. Influence of PPFM on plant growth parameters, yield, capsaicin content and PPFMs population load on phyllosphere and rhizosphere was studied.
\end{abstract}

Aim: This study aimed to assess the plant growth promotional ability and biocontrol efficiency of native pink pigmented facultative methylotrophs (PPFMs) of chilli for management of chilli anthracnose disease through induced systemic resistance mechanism under pot culture experiments.

Results: The results of $16 \mathrm{~S}$ rRNA gene sequence analysis revealed selected isolates as Methylobacterium populi (PPFM6) and Methylobacterium radiotolerans (PPFM170). The ISR molecules tested were significantly influenced by PPFM isolates. The peroxidase and phenyl alanine ammonia lyase (PALase) activity increased from 1 DAI to 7 DAl whereas chitinase, polyphenol oxidase (PPO) and phenol contents increased upto $5 \mathrm{DAl}$, after which gradual decrease was noticed. Inoculation of PPFMs to chilli crop significantly improved plant height, dry matter and chlorophyll content. Significantly lesser disease incidence, more yield and more capsaicin content was observed with application of M. populi as compared to control.

Interpretation: The present study highlights native M. populi (PPFM6) of chilli as an effective plant growth promoter, exhibiting significant biocontrol efficiency against $C$. capsici.

Key words: Anthracnose, Chilli, Facultative methylotrophs, Induced Systemic Resistance, Methylobacterium

How to cite : Santosh, S. and M.N. Sreenivasa: Molecular characterization of native pink pigmented facultative methylotrophs of chilli and their induced systemic resistance mechanism in management of anthracnose. J. Environ. Biol., 41, 1493-1500 (2020). 


\section{Introduction}

Chilli (Capsicum annum) is one of the most essential spicy vegetable cultivated throughout the world. Its production is affected by various biotic stresses, among which anthracnose caused by Colletotrichum capsici (C. capsici) is a major constraint affecting quantitative and qualitative chilli production, world-wide. The disease is reported to affect almost all the aerial parts of the plant. The disease is seed and soil borne, which primarily affects the ripe fruits with significant damage at green stage (Agrios, 2005). Although different chemical fungicides are being used to control Colletotrichum sp., excessive use of chemicals have resulted in environmental pollution, high human health risk and development of resistant pathogenic strains (Staub, 1991; Komarek et al., 2010) apart from increased cost of cultivation. There is a pressing need for a novel and sustainable alternative which can help in achieving drastic cutback in use of harmful chemical pesticides. In this regard, management of plant diseases through antagonistic microorganisms can be an effective and sustainable alternative (Cook and Baker, 1983).

Development of bio-agents requires extensive study and understanding complex interaction among biocontrol agents and plants. Variety of biocontrol agents like Bacillus sp., Pseudomonas sp., Trichoderma sp. (Trabelsi and Mhamdi, 2013; Cha et al., 2016) have been commercialized for different crops, which are mainly isolated from the rhizosphere soil, and phyllosphere microorganisms were not intensively studied to understand their biocontrol capabilities. The phyllosphere is more hostile for biocontrol agents to establish as it is directly exposed to fluctuating environmental conditions with limited nutrient resources. Phyllosphere microorganisms include both pathogenic and non-pathogenic organisms. Among phyllosphere microbial population, pink pigmented facultative methylotrophs (PPFMs) are of great interest and are distinguished based on formation of pink to red colonies on selective isolation media (Hiraishi et al., 1995). PPFMs comprise mainly the genus Methylobacterium and are known to utilize both single and multi-carbon compounds as carbon and energy source. PPFMs are associated with the roots, leaves and seeds of most terrestrial plants and many are known to be phytosymbionts (Trotsenko et al., 2001).

Studies have proven their plant growth promotional abilities directly by producing plant growth promoting hormones like indole 3-acetic acid (IAA), gibberellic acid (GA), cytokinins and showing 1-aminocyclopropane1-carboxylate (ACC) deaminase activity (Yim et al., 2012; Savitha et al., 2013, 2019; Priya et al., 2019; Vadivukkarasi and Bhai, 2019). They are known to produce significant amount of IAA $\left(0.14\right.$ to $19.77 \mathrm{\mu g} \mathrm{m}^{-1}$ of culture filtrate) and GA (4.77 to $128.28 \mu \mathrm{g} \mathrm{ml}^{-1}$ of culture filtrate) (Savitha et al., 2013). They assist plants in fighting the phytopathogens by producing siderophores, hydrogen cyanide (HCN) and induced systemic resistance (ISR) mechanisms (Madhaiyan et al., 2005, 2006). ISR is a broad term wherein resistance is triggered in plants by activating defense mechanisms by biological or chemical inducers, which protect plants from pathogen and insect attack. Induction of defense responses by PPFMs is mainly coupled with the production of pathogenesis-related (PR) proteins like $\beta$-1,3-glucanase and chitinase, defense enzyme phenylalanine ammonia lyase (PALase) and oxidative enzymes like peroxidase and polyphenol oxidase (PPO). Mechanism of ISR is well studied in tomato against plant pathogens Pseudomonas syringae pv. tomato (Indiragandhi et al., 2008) and Fusarium oxysporum f.sp. lycopersici, Sclerotium rolfsii, Pythium ultimum and Rhizoctonia solani (Janahiraman et al., 2016). Even though there are few studies on plant growth promotional abilities of PPFMs in chilli, but they have not been explored for management of chilli anthracnose. Hence, the present study was planned to characterize selected native PPFM isolates of chilli through $16 \mathrm{~s}$ rRNA sequencing and to assess their biocontrol efficiency against chilli anthracnose under pot culture.

\section{Materials and Methods}

PPFM strains and inoculum preparation: PPFM strains were isolated from disease-free chilli (Capsicum annum L.) plants in anthracnose infected areas of North Karnataka and morphologically characterized (Savitha et al., 2013). Thirty isolates were screened for functional characteristics like IAA, GA (Savitha et al., 2013) cytokinin production, phosphorous solubilisation (Savitha et al., 2019) and biocontrol efficiency against major pathogens of chilli (Savitha et al., 2015). The selected PPFMs bioinoculant was prepared by inoculating $72 \mathrm{hr}$ old log phase culture in ammonium mineral salts (AMS) broth (Whittenburry et al., 1970). The flasks were kept in a temperature controlled shaker at $28 \pm 2^{\circ} \mathrm{C}$ for five days to get a population of $10^{9} \mathrm{cfu} \mathrm{ml}^{-1}$ of liquid culture. For seed treatment, culture broth was mixed with sterilized lignite powder at 1:3 ratios. $1 \mathrm{~kg}$ carrier based inoculant was mixed with 15 litres of sterilized distilled water for seedling dip. Spraying inoculum was diluted at 1:1 ratio with sterilized distilled water. Fungal pathogen (C. capscisi) causing anthracnose in chilli was isolated from infected chilli fruits by transferring infected portions aseptically to petriplate containing potato dextrose agar (PDA) medium. Pathogenicity tests were carried out by artificially inoculating pathogen to chilli fruits by pin pricking method. Koch's postulates were confirmed by re-isolating pathogen from diseased tissue. Mycelia and spores of $C$. capsici $\left(2 \times 10^{4}\right.$ conidia $\left.\mathrm{ml}^{-1}\right)$ were harvested from potato dextrose agar grown 10-day-old culture and a suspension was prepared with sterilized distilled water.

Pot culture studies: A pot culture experiment was planned in completely randomized design (CRD) with two efficient native PPFM strains of chilli along with reference strain with eight replications. Seeds treated with PPFMs $\left(20 \mathrm{~g} \mathrm{~kg}^{-1}\right.$ seeds) were sown in nursery bed of size $1 \mathrm{~m} \times 1 \mathrm{~m}$. The 45 -day-old seedlings were uprooted and dipped in PPFMs inoculum slurry for $30 \mathrm{~min}$ before transplanting them to earthen pots. Transplanting was carried out at the rate of two seedlings per earthen pot of $30 \mathrm{~cm}$ diameter containing $10 \mathrm{~kg}$ sterilized soil. Foliar application of PPFMs was undertaken at the rate of $25 \mathrm{ml}$ per plant at 30,45 and 
60 days after transplanting (DAT). The pathogen was challenge inoculated by placing $15 \mu \mathrm{l}$ of mycelium and spore suspension of C. capsici on the wound punctured by a needle at the middle of chilli leaves. After inoculation, the seedlings were covered with plastic bags for two days to avoid loss of moisture (Oanh et al., 2006). PPFMs uninoculated and plants treated with pathogen alone served as control.

Induction of systemic resistance: The plant leaves were collected at different time intervals viz., 1, 3, 5, 7 and 9 days after pathogen inoculation (DAI) and immediately homogenized with liquid nitrogen. The powder was extracted with $10 \mathrm{ml}$ of chilled $0.1 \mathrm{M}$ sodium phosphate buffer ( $\mathrm{pH} 7.0$ ) using sterilized pestle and mortar. The mixture was centrifuged at 10,000 rpm for $30 \mathrm{~min}$ and supernatant was used as a crude enzyme extract for assaying peroxidase, polyphenol oxidase (PPO) and phenylalanine ammonia-lyase (PALase). Oxidative enzymes like peroxidase and PPO were estimated as per Mahadevan and Shridhar (1986) and Mayer et al. (1965), respectively.

The activity of peroxidase and PPO were expressed as change in unit of absorbance at $436 \mathrm{~nm}$ and $420 \mathrm{~nm}$, respectively. The enzyme activity was expressed as change in optical density per gram protein per minute. PALase activity was measured using the procedure described by Ross and Sederoff (1992). The absorbance of toluene phase containing trans-cinnamic acid was measured at $295 \mathrm{~nm}$ against the blank of toluene. Enzyme activity was expressed as $\mu \mathrm{g}$ trans-cinnamic acid released $\min ^{-1} \mathrm{~g}^{-1}$ fresh weight. Chitinase activity was assayed by using $2 \mathrm{ml}$ of sodium citrate buffer $0.1 \mathrm{M}$ ( $\mathrm{pH} 5.0$ ) for crude enzyme extraction. The release of $\mathrm{N}$-acetyl-glucosamine (GlcNAc) was measured by spectrophotometer at $540 \mathrm{~nm}$ (Miller, 1959) and expressed as $\llbracket \mathrm{g}$ GIcNAc equivalents released $\mathrm{min}^{-1} \mathrm{mg}^{-1}$ of fresh weight. Phenolic compounds were measured by using one gram of oven dried leaf tissue. Leaves were homogenized in $10 \mathrm{ml}$ of $80 \%$ methanol and agitated for $15 \mathrm{~min}$ at $70^{\circ} \mathrm{C}$ and then filtered.

The extracts were pooled and alcohol evaporated on a hot water bath. The methanolic extract was used for estimating total phenol content in leaves by following Folin Cio-calteau method (Sadasivam and Manickam, 1992). The blue colour developed was read at $650 \mathrm{~nm}$ on a UV visible spectrophotometer. The amount of phenol present in the sample was calculated by referring to a standard curve prepared using catechol and the content was expressed as $\mathrm{mg} \mathrm{g}^{-1} \mathrm{~d}$. wt.

Plant parameters and microbial population: Plant height, population dynamics of PPFMs (rhizosphere and phyllosphere) and chlorophyll content was recorded at 30, 60, 90 and 130 DAT. Single photoelectric analyzing diode (SPAD) was used for determining chlorophyll content. The population was enumerated by employing serial dilution and plating technique. The colonies appearing on the plates after $72 \mathrm{hr}$ of incubation at $30^{\circ} \mathrm{C}$ were counted and expressed as number of cfu $\mathrm{g}^{-1}$ sample. The total dry matter was measured at the time of harvesting (130 DAT) by oven drying samples at $70^{\circ} \mathrm{C}$ till constant weight was achieved.
Disease intensity: Anthracnose incidence was recorded by scoring five plants in each replication using 0-9 scale (Mayee and Datar, 1986). Percent disease index (PDI) was calculated with the disease scales by the formula given by Wheeler (1969).

Sum of the individual disease ratings

Percent disease index (PDI) = ------ $\times 100$

Number of fruits/leaves $\times$ Maximum disease grade

Number of fruits infected

Percent fruit rot infection $($ FRI) = --------------------------- $\times 100$

Total number of fruits observed

Analysis of 16S rRNA gene sequence: Genomic DNA was prepared from PPFM isolates and PCR amplified 16S rRNA genes were purified and sequenced using both $1 F$ and $1 R$ for forward and reverse reactions, respectively. Sequencing was carried out employing a dideoxy cycle with fluorescent terminators and run in a 3130xl Applied Biosystems ABI prism automated DNA sequencer. Comparison of partial 16S rRNAgene sequences was done with the sequences available in $\mathrm{NCBI}$ database. $16 \mathrm{~S}$ rRNA gene sequence similarity of $\geq 97 \%$ was taken for identification of isolates upto species level. Sequence alignment and comparison were performed using multiple sequence alignment tool CLUSTAL W2 (Thompson et al., 1994) with default parameters. The nucleotide sequences were deposited in the GenBank and the accession numbers were obtained.

Statistical analyses: The experimental data were subjected to Completely Randomized Design (CRD) analysis as described by Yates et al. (1937). The level of significance used in 'F' and 'T' test was $P=0.01$. Critical difference values were calculated whenever the 'F' test values were significant.

\section{Results and Discussion}

Two efficient isolates (PPFM6 and PPFM170) were selected based on their plant growth promotional abilities like production of IAA, GA (Savitha et al., 2013), Cytokinin, P solubilization (Savitha et al., 2019) and biocontrol efficiency against major pathogens of chilli (Savitha et al., 2015). These isolates showed the highest 16SrRNA gene sequence similarities to strains of M. populi z68b (97\%) and M. radiotolerans PPFG1 $(99 \%)$, respectively, and the nucleotide sequences were deposited in the GenBank and the accession numbers were obtained (Table 1). These two isolates were explored for plant growth promotional ability and biocontrol efficiency against chilli phytopathogen C. capsiciunder pot culture.

The effect of inoculation of PPFMs on plant growth parameters like plant height and chlorophyll content were recorded at various stages of crop growth viz. 30, 60, 90 and 130 DAT whereas dry matter content was recorded at 130 DAT. Significant variation in plant height and chlorophyll content was 
Table 1: Potential native PPFM isolates and their phylogenetic relationship

\begin{tabular}{lllll}
\hline Isolates code & Place & Habitat & $\begin{array}{l}\text { Nearest phylogenetic neighbour } \\
\text { (degree of similarity) }\end{array}$ & $\begin{array}{l}\text { Gene Bank } \\
\text { accession number }\end{array}$ \\
\hline PPFM6 & Annigeri, Karnataka, India & Phyllosphere & Methylobacterium populi z68b (97\%) & KC902788 \\
PPFM170 & Savanur, Karnataka, India & Phyllosphere & Methylobacterium radiotolerans PPFG1 (99\%) & KC902789 \\
\hline
\end{tabular}

Table 2: Influence of native PPFMs on chlorophyll content, plant height and total dry matter production in chilli

\begin{tabular}{|c|c|c|c|c|c|c|c|c|c|}
\hline \multirow{3}{*}{ Treatments } & \multicolumn{4}{|c|}{ Chlorophyll content (SPAD value) } & \multicolumn{4}{|c|}{ Plant height $(\mathrm{cm})$} & \multirow{3}{*}{$\begin{array}{l}\text { Total dry } \\
\text { matter (g per plant) } \\
\text { at } 130 \text { DAT }\end{array}$} \\
\hline & 30 & 60 & 90 & 130 & 30 & 60 & 90 & 130 & \\
\hline & DAT & DAT & DAT & DAT & DAT & DAT & DAT & DAT & \\
\hline PPFM6 + C. capsici & 24.50 & 35.20 & 28.90 & 24.90 & 28.50 & 51.80 & 62.50 & 80.50 & 84.50 \\
\hline PPFM170 + C. capsici & 23.00 & 33.60 & 27.25 & 23.20 & 27.40 & 50.00 & 62.00 & 79.80 & 84.00 \\
\hline M. extorquens AM $1+C$. capsici & 23.00 & 31.50 & 24.50 & 20.00 & 26.00 & 48.00 & 57.90 & 74.00 & 79.80 \\
\hline Control & 22.00 & 28.00 & 19.00 & 13.00 & 23.50 & 43.00 & 50.00 & 55.00 & 65.00 \\
\hline S.Em + & 0.34 & 0.30 & 0.32 & 0.29 & 0.26 & 0.40 & 0.47 & 0.40 & 0.39 \\
\hline $\mathrm{CD}(0.01)$ & 1.36 & 1.22 & 1.29 & 1.17 & 1.01 & 1.57 & 1.82 & 1.54 & 1.54 \\
\hline
\end{tabular}

DAT- days after transplanting; all the values are means of 8 replications

observed between PPFMs treated and control chilli plants. The native isolate $M$. populi inoculated plants recorded significantly higher plant height and chlorophyll content compared to other treatments. Whereas control plants showed least plant height and chlorophyll content at all stages of crop growth (Table 2). Native isolates, M. populi (84.5 g per plant) and M. radiotolerans (84 g per plant) recorded significantly higher dry matter content compared to AM1 (79.8 g per plant) and control ( $65 \mathrm{~g}$ per plant). This might be attributed to higher production of plant growth regulators like IAA, GA, cytokinin and $P$ solubilisation ability by $M$. populi (Savitha et al., 2013; 2019). Growth promotional ability of PPFMs is widely reported across crops including cotton, sugarcane (Madhaiyan et al., 2005), and their inoculation was found to increase the photosynthetic activity by enhancing the number of stomata, chlorophyll concentration and malic acid content of crops (Cervantes- Martinez et al., 2004).

Estimation of population load of PPFMs on phyllosphere and rhizosphere at various stages of crop growth viz. 30, 60, 90 and 130 DAT revealed higher population PPFMs in phyllosphere than rhizosphere at all crop stages (Table 3). The higher population on phyllosphere indicates their potential in utilizing the gaseous methanol emitted through stomatal openings during leaf expansion by pectin demethylation (Nemecek-Marshall et al., 1995). In addition, foliar spray of PPFMs at different intervals (30, 45 and 60 DAT) might have positively influenced their population on phyllosphere. There was gradual increase in population upto 90 DAT and declined later. In chilli plants inoculated with M. populi, the higher PPFMs population was recorded both in rhizosphere and phyllosphere at all crop stages compared to other treatments and diseased control showed very least population (Table 3). Biocontrol efficiency of native PPFMs against $C$. capsici was characterized based on their ability to produce ISR molecules. The inoculation of $M$. populi and $M$. radiotolerans induced increased level of ISR molecules over reference strain and control (Fig 1A-1E). Among native isolates, chilli plants inoculated with $M$. populi recorded highest activity of peroxidise, PPO, PALase, chitinase and phenol content enzyme compared to $M$. radiotolerans. Significant increase in the activity of ISR molecules was reported when plants were inoculated with different bioagents and challenged with pathogens across crop species (Nielsen et al., 1998; Xue et al., 1998; Nandakumar et al., 2001).

The highest activity of peroxidase and PALase was observed on $7^{\text {th }}$ day after challenge inoculation with pathogen (Fig $1 A, B)$ and in case of PPO, chitinase enzymes and phenol content, the highest activity was recorded on 5th day after challenge inoculation with pathogen (Fig $1 \mathrm{C}, \mathrm{E})$ after which there was a gradual decrease. The early and increased expression of peroxidase in this study would have facilitated the biochemical reaction necessary for lignification and production of hydrogen peroxide and other free radicals with antimicrobial effect (Hammerschmidt and Kuc, 1982) which might have restricted the development of $C$. capsici. Another important defense enzyme, PALase showed increased activity after a day of challenge inoculation with $C$. capsici upto 7 days and decreased later. Cinnamic acid, a product of PALase is linked to cell lignification and the highest level of PALase occurred approximately $24 \mathrm{hr}$ after initial infection of Fusarium udum in pigeon pea (Podile and Laxmi, 1998). Peroxidase and PPO catalyzes the oxidation of phenolic compounds through PPO-PO- $\mathrm{H}_{2} \mathrm{O}_{2}$ system (Srivastava, 1987). Induction of PPO activity had resulted in resistance response in this study has been observed earlier by Thipyapong et al. (2007) and Jung et al. (2011). 
Table 3: Population dynamics of PPFMs in rhizosphere soil and phyllosphere at different stages of chilli growth

\begin{tabular}{lllllllll}
\hline \multirow{2}{*}{ Treatment details } & \multicolumn{3}{c}{ Rhizosphere soil (10 cfu g $^{-1}$ soil) } & \multicolumn{4}{c}{ Phyllosphere (10 cfu g $^{-1}$ leaf) } \\
\cline { 2 - 9 } & 30 DAT & 60 DAT & 90 DAT & 130 DAT & 30 DAT & 60 DAT & 90 DAT & 130 DAT \\
\hline PPFM6 + C. capsici & 14.22 & 16.53 & 17.50 & 10.02 & 35.20 & 43.50 & 46.20 & 38.32 \\
& $(5.15)$ & $(5.22)$ & $(5.24)$ & $(5.00)$ & $(5.55)$ & $(5.64)$ & $(5.66)$ & $(5.58)$ \\
PPFM170 + C. capsici & 13.95 & 16.32 & 16.90 & 9.32 & 34.70 & 42.00 & 44.70 & 37.15 \\
& $(5.14)$ & $(5.21)$ & $(5.23)$ & $(4.97)$ & $(5.54)$ & $(5.62)$ & $(5.65)$ & $(5.57)$ \\
M. extorquens AM 1+ C. capsici & 12.95 & 15.13 & 15.85 & 9.00 & 34.15 & 41.26 & 41.21 & 35.13 \\
& $(5.11)$ & $(5.18)$ & $(5.2)$ & $(4.95)$ & $(5.53)$ & $(5.62)$ & $(5.61)$ & $(5.55)$ \\
Control & 5.4 & 5.7 & 3.00 & NP & 14.12 & 14.23 & 5.20 & NP \\
& $(4.73)$ & $(4.76)$ & $(4.48)$ & & $(5.15)$ & $(5.15)$ & $(4.72)$ & \\
\hline
\end{tabular}

Figures in the parentheses are log transformed values; NP - No population of PPFM; DAT- Days after transplanting, all the values are means of 8 replications

Table 4: Impact of PPFMs on anthracnose incidence, yield and capsaicin content of chilli

\begin{tabular}{lllll}
\hline Treatment details & Percent fruit rot & Percent disease index & Yield (q ha $\left.{ }^{-1}\right)$ & Capsaicin content (\%) \\
\hline PPFM6 + C. capsici & $58.00(49.60)$ & $56.50(48.73)$ & 1.59 & $0.14(2.14)$ \\
PPFM170 + C. capsici & $59.80(50.65)$ & $60.00(50.77)$ & 1.50 & $0.14(2.14)$ \\
M. extorquens AM 1+ C. capsici & $63.00(52.54)$ & $62.00(51.94)$ & 1.26 & $0.11(1.90)$ \\
Control (only C. capsici ) & $70.00(56.79)$ & $75.00(60.00)$ & 1.00 & $0.10(1.81)$ \\
S.Em + & 0.32 & 0.45 & 0.02 & 0.002 \\
CD $(0.01)$ & 1.01 & 1.52 & 0.06 & 0.007 \\
\hline
\end{tabular}

Values in the parentheses are arc sine transformed, all the values are means of 8 replications

The accumulation of chitinase resulted in acquisition of resistance to C. capsici. Plants produce chitinase (Santos et al., 2004) responsible for degradation of chitin, which is a major component of fungal cell and thereby destroy cell wall integrity eventually limiting the growth of pathogen. These enzymes are important determinants of resistance of plants to fungal diseases (Funnell et al., 2004). Our study revealed association of increased phenolic content with disease suppression (or increased resistance) to C. capsici. This is in agreement with the previous reports on PGPR Trichoderma viridae, Penicillium chrysogenum and Saccharomyces cerevisiae against blight disease caused by Botrytis allii in onion (Hussein et al., 2018). Many phenolic compounds are known for their antimicrobial activities and function as precursors to structural polymers such as lignin or serve as signal molecules to activate plant defense genes (Dakora, 1996).

The intensity of anthracnose disease in chilli was calculated by FRI and PDI. Chilli plants inoculated with M. populi and challenged with $C$. capsici recorded $56.50 \mathrm{PDI}$, followed by $60 \mathrm{PDI}$ observed in M. radiotolerans. Plants challenge inoculated with only pathogen showed 75.00 PDI (Table 4). M. populi treated chilli plants recorded $58.00 \% \mathrm{FRI}$ whereas $M$. radiotolerans inoculated chilli plants showed $59.80 \%$ FRI. The highest fruit rot $(70.00 \%)$ was observed in plants challenge inoculated with only pathogen. The direct antagonistic activity of $M$. populi and $M$. radiotolerans by inhibiting mycelial growth of $C$. capsici (Savitha et al., 2015) and indirect mechanism of C. capsici inhibition by induction of increased ISR molecules like peroxidise, PALase, PPO, chitinase and phenol content in case M. populi and $M$. radiotolerans compared to other treatments could be the possible reasons for decreased disease incidence. The findings are in congruence with the findings of Lawrence et al. (1996), as quantum of accumulation or rapidity of induction of ISR molecules in plants is directly correlated with degree of disease resistance. Previously, several studies have reported the induction of ISR molecules like chitinase, PALase, $\beta$-1,3-glucanase, peroxidase and PPO in rice, peanut and tomato plants due to methylobacterial inoculation against various pathogens (Madhaiyan et al., 2004, 2006; Indiragandhi et al., 2008). M. populi inoculation showed significant difference with respect to yield of chilli (1.59 $\left.\mathrm{q} \mathrm{ha}^{-1}\right)$ followed by $M$. radiotolerans ( $\left.1.50 \mathrm{q} \mathrm{ha}^{-1}\right)$. The lowest yield $\left(01.00 \mathrm{q} \mathrm{ha}^{-1}\right)$ was recorded in control plants. The export quality of chilli is mainly assessed by their capsaicin content. Inoculation of $M$. populi and $M$. radiotolerans showed significant difference in capsaicin content compared to AM1 and control (Table 4). The improvement in yield and yield parameters of PPFMs treated plants is directly associated to their plant growth promotional ability and disease suppression. The selection of biocontrol agents against any pathogen is based on their antagonistic properties as well as plant growth promoting abilities to achieve suppression of disease and improvement in 

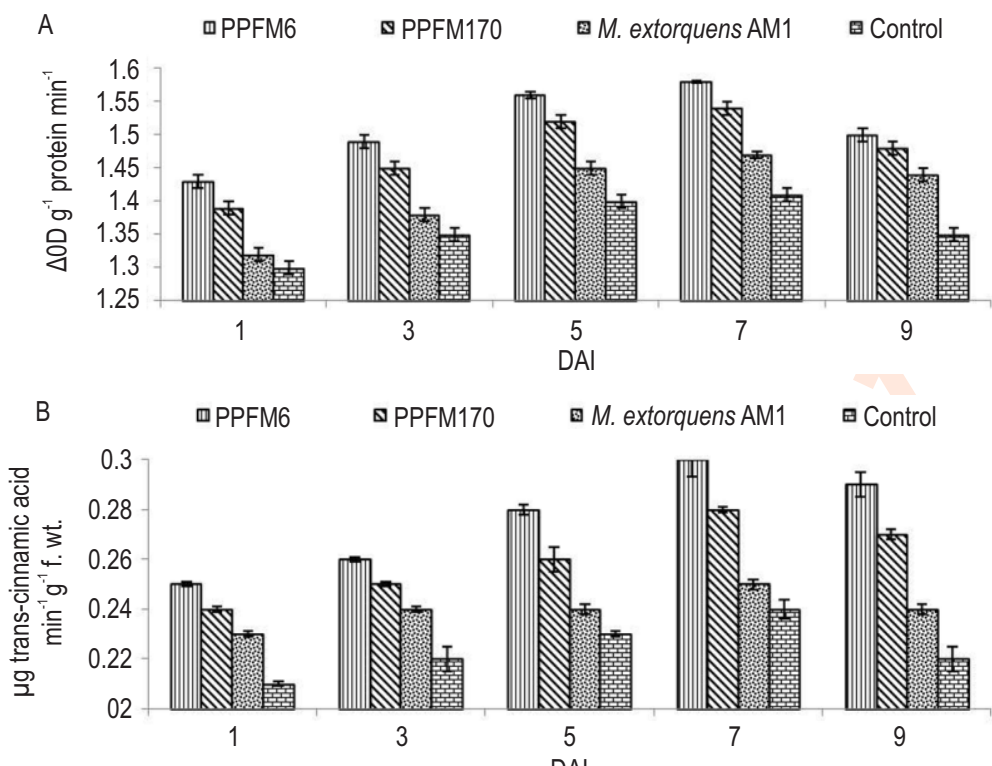


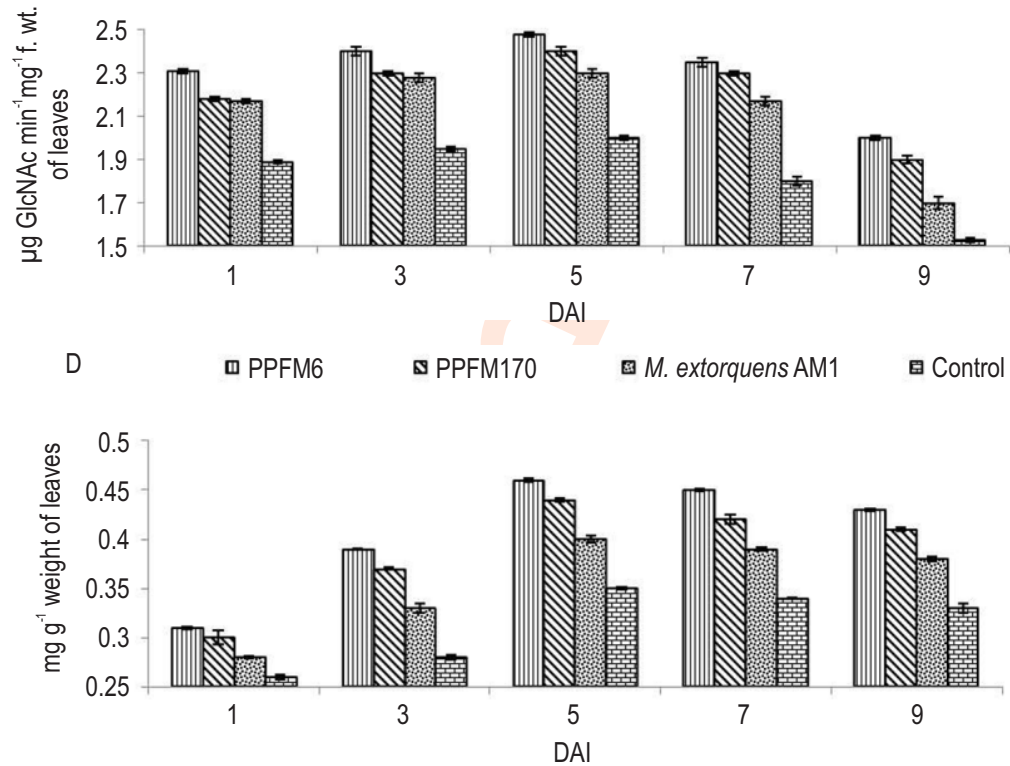

E $\quad$ aPPFM6 $\quad$ aPPM170 extorquens AM1 $\quad$ (Control

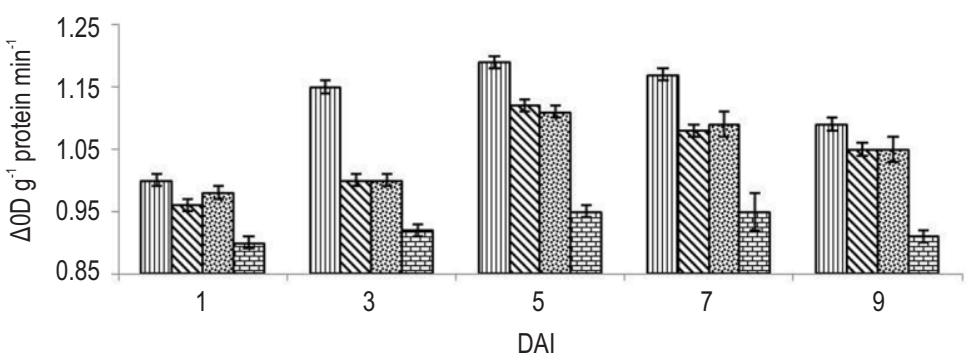

Fig. 1: Induction of systemic resistance by native PPFM isolates: (A) Peroxidase activity; (B) PALase activity; (C) Chitinase activity; (D)Phenol content and (E) PPO activity (Note: DAl-Days after challenge inoculation of pathogen). 
yield. The present study revealed that inoculation of selected native isolates of PPFM ( $M$. populi and $M$. radiotolerans) to chilli plants resulted in significant growth promotion by influencing plant growth parameters like plant height, total biomass and chlorophyll content as compared to uninoculated plants. These native PPFM isolates also exhibited significant biocontrol efficiency against $C$. capsici by producing plant defence molecules like peroxidise, PPO, PALase, chitinase and phenolic content. To the best of our knowledge, this is a first report on exploration of native PPFMs for the sustainable management of chilli anthracnose. This study further highlight, among different native PPFMs of chilli, M. populi as an effective plant growth promoter, exhibiting significant biocontrol efficiency against $C$. capsici as compared to other isolates. Exploring beneficial microorganisms is an important component of integrated disease management and sustainable agriculture. The information generated in the present study and identified efficient strain would facilitate sustainable chilli production and effective management of anthracnose disease.

\section{Acknowledgments}

Authors gratefully acknowledge the necessary facilities provided at U.A.S., Dharwad, Karnataka for carrying out the present study. First author thank the Indian Council of Agricultural Research (ICAR), New Delhi for providing financial assistance in the form of Senior Research Fellowship (SRF) for her Ph. D. Programme.

\section{References}

Agrios, G.N.: Plant Pathology. $5^{\text {th }}$ Edn., Elsevier Academic Press, Amsterdam (2005)

Cervantes-Martinez, J., S. Lopez-diaz and B. Rodriguez-garay: Detection of the effects of Methylobacterium in Agave tequilana Weber var. azul by laser induced fluorescence. Plant Sci., 166, 889-892 (2004).

Cha, J.Y., S. Han, H.J. Hong, H. Cho, D. Kim, Y. Kwon, S.K. Kwon, M. Crusemann, Y. Bok Lee, J. F. Kim, G. Giaever, C. Nislow, B.S. Moore, L.S. Thomashow, D. M. Weller and Y. S. Kwak: Microbial and biochemical basis of a Fusarium wilt-suppressive soil. ISME J., 10, 119-129(2016).

Cook, R.J. and K.F. Baker: The nature and practice of biological control of plant pathogens. $3^{\text {rd }}$ Edn., American Phytopathological Society, Minnesota (1983).

Dakora, F.D.: Diverse functions of isoflavonoids in legumes transcend anti-microbial definitions of phytoalexin. Physiol. Mol. Plant. Pathol., 49, 1-20 (1996).

Funnell, D.L., C.B. Lawrence, J.F. Pedersen and C.L. Schardl: Expression of the tobacco $\beta$-1,3-glucanase gene, PR-2d, following induction of SAR with Peronospora tabacina. Physiol. Mol. Plant Pathol., 65, 285-296 (2004).

Hammerschmidt, R. and J.A. Kuc: Lignification as a mechanism for induced systemic resistance in cucumber. Physiol. Plant Pathol., 20,61-71 (1982).

Hiraishi, A., K. Furuchi, A. Matsumoto, K.A. Koike, M. Fukuyama and K. Tabuchi: Phenotypic and genetic diversity of chlorine-resistant Methylobacterium strains isolated from various environments. Appl. Environ. Microbiol., 61, 2099-2107 (1995).
Hussein, M.M.A., K.A.M. Abo-Elyousr, M.A.H. Hassan, M. Hashem, E.A. Hassan and S.A.M. Alamri: Induction of defense mechanisms involved in disease resistance of onion blight disease caused by Botrytis allii. Egypt. J. Biol. Pest Control, 28, 80 (2018).

Indiragandhi, P., R. Anandham, K.Y. Kim and W.J. Yim: Induction of systemic resistance by modulating ethylene biosynthesis pathway by ACC deaminase containing Methylobacterium oryzae against Pseudomonas syringae in tomato. World J. Microbiol. Biotechnol., 24, 1037-1045 (2008).

Janahiraman, V., R. Anandham, S.W. Kwon, S. Sundaram, V.K. Pandi, R. Krishnamoorthy, K. Kim, S. Samaddar and T. Sa: Control of wilt and rot pathogens of tomato by antagonistic pink pigmented facultative methylotrophic Delftia lacustris and Bacillus spp. Front. Plant Sci., 7, 1626 (2016)

Jung, W. J., R.D. Park, F. Mabood, A.L. Souleimanov and D. Smith: Effects of Pseudomonas aureofaciens on defense responses in soybean plants infected by Rhizoctonia solani. J. Microbiol. Biotechnol., 21, 379-386 (2011).

Komarek, M., E. Cadkova, V. Chrastny, F. Bordas and J.C. Bollinger: Contamination of vineyard soils with fungicides: A review of environmental and toxicological aspects. Environ. Int., 36, 138 $151(2010)$

Lawrence, C.B., M.H.A.J. Joosten and S. Tuzun: Differential induction of pathogenesis-related proteins in tomato by Alternaria solani and the association of a basic chitinase isozyme with resistance. Physiol. Mol. Plant Pathol., 48, 361-377 (1996).

Madhaiyan, M., B.V. Sureshreddy, R. Anandam, M. Senthilkumar, S. Poonguzhali and S.P. Sundaram: Plant growth promoting Methylobacterium induces defense responses in ground nut (Arachis hypogaea L.) compared with root pathogen. Curr. Microbiol., 53, 270-276 (2006).

Madhaiyan, M., S. Poonguzhali, M. Senthilkumar, S. Seshadri, H. Chung, J. Yang, P. Sundaram and T. Sa: Growth promotion and induction of systemic resistance in rice cultivar Co-47 (Oryza sativa L.) by Methylobacterium spp. Bot. Bull. Acad. Sin., 45, 315-324 (2004).

Madhaiyan, M., S. Poonguzhali, S.P. Sundaram and S.A. Tongmin: A new insight into foliar applied methanol influencing phylloplane methylotrophic dynamics and growth promotion of cotton (Gossypium hirsutum L.) and sugarcane (Saccharum officinarum L.). Environ. Expt. Bot., 57, 168-176 (2005).

Mahadevan, A. and R. Sridhar: Methods in Physiological Plant Pathology. ${ }^{\text {rd }}$ Edn., Sivakami Publications, Chennai (1986).

Mayee, C.D. and V.V. Datar: Phytopatholometry. Marathwada Agric. Univ., Parbhani, Technical Bulletin-1, pp. 16-24 (1986).

Mayer, A.M., E. Harel and R.B. Shaul: Assay of catechol oxidase, a critical comparison of methods. Phytochemistry, 5, 783-789 (1965).

Miller, G.I.: Use of dinitrosalicylic acid reagent for determination of reducing sugar. Anal. Chem., 31, 426-428 (1959).

Nandakumar, R., S. Babu, R. Viswanathan and T. Raguchander: Induction of systemic resistance in rice against sheath blight disease by plant growth promoting rhizobacteria. Soil Biol. Biochem., 33, 603-612 (2001).

Nemecek-marshall, M., R.C. MacDonald, J.J. Franzen, C.L. Wojciechowski and R. Fall: Methanol emission from leaves: Enzymatic detection of gas-phase methanol and relation of methanol fluxes to stomatal conductance and leaf development. Plant Physiol., 108, 1359-1368 (1995).

Nielsen, M.N., J. Sorenson, J. Fels and H.C. Pedersen: Secondary metabolite and endo-chitinase dependent antagonism towards plant-pathogenic micro fungi of Pseudomonas fluorescence isolates from sugar beet rhizosphere. Appl. Environ. Microbiol., 64, 3563-3569 (1998). 
Oanh, L.T.K., V. Korpraditskul, C. Rattanakreetakul and S. Wasee: Influence of biotic and chemical plant inducers on resistance of chilli to anthracnose. Kasetsart J. Nat. Sci., 40, 39-48 (2006).

Podile, A.R. and V.D.V. Laxmi: Seed bacterization with Bacillus subtilis AF1 increase phenylalanine ammonia lyase and reduces the incidence of Fusarial wilt in pigeonpea. J. Phytopathol., 146, 255259 (1998).

Priya, M., K. Kumutha and M. Senthilkumar: Impact of bacterization of Rhizobium and Methylobacterium radiotolerans on germination and survivability in groundnut seed. Int. J. Curr. Microbiol. App. Sci., 8, 394-405 (2019).

Ross, W.W. and R.R. Sederoff: Phenylalnine ammonia lyase activity from lobally pine: Purification of the enzyme and isolation of complementary DNA clones. Plant Physiol., 98, 380-386 (1992).

Sadasivam, S. and A. Manickam: Biochemical Methods for Agriculture Science. Wiley Eastern Limited, New Delhi (1992).

Santos, I. S., O.L.T. Machado, M. Da Cunha and V.M. Gomes: A chitinase from Adenanthera pavonina L. seeds: Purification, characterization and immunolocalization. Plant Sci., 167, 12031210 (2004).

Savitha, P., M.N. Sreenivasa and J.P. Nirmalnath: In-vitro screening for biocontrol activity of pink pigmented facultative methylotrophs against phytopathogens. Karnataka J. Agri. Sci., 28, 286-287 (2015).

Savitha, P., M.N. Sreenivasa and J.P. Nirmalnath: Production of plant growth hormones by pink pigmented facultative methylotrophs. $J$. Pure Appl. Microbiol., 7, 981-985 (2013).

Savitha, S., H.B. Santosh and M.N. Sreenivasa: Assessment of native pink pigmented facultative methylotrophs of chilli (Capsicum annuum L.) for their plant growth promotional abilities. Int. J. Curr. Microbiol. App. Sci., 8, 1196-1205(2019).

Srivastava, S.K.: Peroxidase and polyphenol oxidase in Brassica juncea injected with Macrophomina phaseolina (Tassio) and their implications in disease resistance. J. Phytopathol., 120, 249-254 (1987).

Staub, T.: Fungicide resistance: Practical experience and anti-resistance strategies and the role of integrated use. Annu. Rev. Phytopathol., 29, 421-442 (1991).

Thipyapong, P., M.J. Stout and J. Attajarusit: Functional analysis of polyphenol oxidases by antisense/sense technology. Molecules, 12, 1569-1595(2007).

Thompson, J.D., D.G. Higgins and T.J. Gibson: CLUSTAL W: Improving sensitivity of progressive multiple sequence alignments through sequence weighing, position-specific gap penalties and weight matrix choice. NucleicAcids Res., 22, 4673-4680 (1994).

Trabelsi, D. and R. Mhamdi: Microbial inoculants and their impact on soil microbial communities: A review. Biomed. Res. Int., Vol. 2013, Aritcle ID 863240 (2013).

Trotsenko, Y.A., E.G. Ivanova and N.V. Doronina:Aerobic methylotrophic bacteria as phytosymbionts. Microbiology, 70, 623-632 (2001).

Vadivukkarasi, P. and R.S. Bhai: Phyllosphere-associated Methylobacterium: A potential biostimulant for ginger (Zingiber officinale Rosc.) cultivation. Arch. Microbiol., 202, 369-375 (2019).

Wheeler, B.E.J.: An Introduction to Plant Diseases. John Wiley \& Sons Ltd., London (1969).

Whittenburry, R., S.L. Davies and J.F. Wilkinson: Enrichment, isolation and some properties of methane-utilizing bacteria. J. Gen. Microbiol., 61, 205-218(1970).

Xue, L., P.M. Charest and S.H. Jabaji-hare: Systemic induction of peroxidases, $\beta-1,3-$ glucanases, chitinases and resistance in bean plants by binucleate Rhizoctonia species. Phytopathology, 88, 359-365 (1998).

Yates, P., V.G. Panse and P.V. Sukhatme: Statistical Methods for Agricultural Workers. Indian Council of Agricultural Research, New Delhi (1937).

Yim, W., S. Woo, K. Kim and T. Sa: Regulation of ethylene emission in tomato (Lycopersicon esculentum Mill.) and red pepper (Capsicum annuum L.) inoculated with ACC deaminase producing Methylobacterium spp. Korean J. Soil Sci. Fert., 45, 37-42 (2012). 